\title{
Cardamonin induces ROS-mediated G2/M phase arrest and apoptosis through inhibition of NF-kB pathway in nasopharyngeal carcinoma
}

\author{
Yuting Li ${ }^{1}$, You Qin ${ }^{*, 1}$, Chensu Yang ${ }^{1}$, Haibo Zhang ${ }^{2}$, Yong Li ${ }^{3}$, Bian Wu ${ }^{1}$, Jing Huang ${ }^{1}$, Xiaoshu Zhou ${ }^{1}$, Bo Huang ${ }^{4,5}$, Kunyu Yang ${ }^{1}$ and
} Gang Wu ${ }^{1}$

Cardamonin has been demonstrated to have an inhibitory effect in many cancers, but its underlying mechanism remains elusive. Here, we studied, for the first time, the mechanism of cardamonin-induced nasopharyngeal carcinoma cell death both in vitro and in vivo. In our study, we showed that cardamonin inhibited cancer cell growth by inducing G2/M phase cell cycle arrest and apoptosis via accumulation of ROS. NF- $\kappa$ B activation was involved in breaking cellular redox homeostasis. Therefore, our results provided new insight into the mechanism of the antitumor effect of cardamonin, supporting cardamonin as a prospective therapeutic drug in nasopharyngeal carcinoma by modulating intracellular redox balance.

Cell Death and Disease (2017) 8, e3024; doi:10.1038/cddis.2017.407; published online 31 August 2017

Nasopharyngeal carcinoma (NPC) is a carcinoma that occurs in the epithelial lining of the nasopharynx. NPC is an uncommon disease in most countries, whereas it has a high incidence in southern China, northern Africa, and Alaska. ${ }^{1,2}$ Despite significant progress in diagnostics and therapeutics, many patients still succumb to the disease because of metastasis and resistance to chemotherapies, especially for patients in advanced stages. ${ }^{3-5}$ Thus, there is clearly an urgent need to develop effective drugs to treat NPC.

Reactive oxygen species (ROS), products of normal cellular metabolism, play a dual role in living systems. ${ }^{6}$ At low/ moderate concentrations, ROS play a beneficial role, whereas excessive amounts of ROS damage cellular lipids, proteins, and DNA. Elevated levels of ROS have been observed in many types of cancer cells. Increased ROS stress in cancer cells correlates with the aggressiveness of tumors and a poor prognosis. ${ }^{7,8}$ Therefore, cancer cells are more vulnerable to further oxidative insults induced by ROS-generating agents. Thus, it might be possible to preferentially eliminate cancer cells by pharmacological ROS insults without causing significant toxicity to normal cells.

Cardamonin, a chalcone extracted from cardamom spice, exists in many other plant species. ${ }^{9}$ Cardamonin has been reported to have anti-inflammatory and anti-tumor activities. $^{10-14}$ Previously, we and others have shown that cardamonin is effective in many types of cancers. ${ }^{15-19}$ Several studies have demonstrated that cardamonin induced accumulation of ROS in colorectal cancer cells. ${ }^{16}$ Although previous studies suggest that ROS contribute to cardamonin- induced cancer cell death, the exact mechanism remains unexplored.

In the present study, we demonstrated for the first time that cardamonin is effective against NPC cells in vivo and in vitro. Mechanistically, we showed that apoptosis and G2/M phase arrest are involved in the effect of cardamonin in NPC cells. Furthermore, our data revealed that cardamonin inhibits activation of the NF- $\kappa$ B pathway, which in turn triggers ROS accumulation to activate JNK mitogen-activated protein kinase (MAPK). Eliminating ROS partially reversed the apoptosis and G2/M phase arrest induced by cardamonin. Taken together, our findings validate cardamonin as a potential anti-cancer agent and provide evidence of ROS accumulation as an underlying mechanism.

\section{Results}

Cardamonin inhibits viability of NPC cells. Viability of NPC cells was assessed using a CCK-8 assay after treatment with different concentrations of cardamonin for $24 \mathrm{~h}$. These results demonstrated that cardamonin decreased viability of NPC cells in a concentrationdependent manner. The $I_{50}$ values were estimated to be 16.22 $\mu \mathrm{M}$ (CNE-1), 14.34 $\mu \mathrm{M}$ (CNE-2), $16.50 \mu \mathrm{M}$ (HONE-1), and $68.12 \mu \mathrm{M}$ (SUNE-1) as shown in Figure 1a. Treatment with cardamonin at $10 \mu \mathrm{M}$ for 24,48 and $72 \mathrm{~h}$ resulted in an increasing inhibition of viability (Figure 1b). The inhibitory effect of cardamonin on CNE-2 cells was confirmed with a colony formation assay. Our data indicate that cardamonin decreased the formation of CNE-2 cell colonies in a

\footnotetext{
${ }^{1}$ Cancer Center, Union Hospital, Tongji Medical College, Huazhong University of Science and Technology, Wuhan 430022, China; ${ }^{2}$ Department of Radiotherapy, Zhejiang Province People's Hospital, Hangzhou, Zhejiang, China; ${ }^{3}$ Department of Oncology, Renmin Hospital, Hubei University of Medicine, Shiyan, Hubei, China; ${ }^{4}$ Department of Biochemistry and Molecular Biology, Tongji Medical College, Huazhong University of Science and Technology, Wuhan, Hubei, China and ${ }^{5}$ State Key Laboratory of Medical Molecular Biology and Department of Immunology, Institute of Basic Medical Sciences, Chinese Academy of Medical Sciences and Peking Union Medical College, Beijing, China

${ }^{*}$ Corresponding author: Y Qin, Cancer Center, Union Hospital, Tongji Medical College, Huazhong University of Science and Technology, Wuhan 430022, China. Tel: +86 2765 650086; Fax: +86 2765 650733; E-mail: qinyoudoc@ 163.com Received 20.1.17; revised 27.6.17; accepted 04.7.17; Edited by Mads Daugaard
} 
a

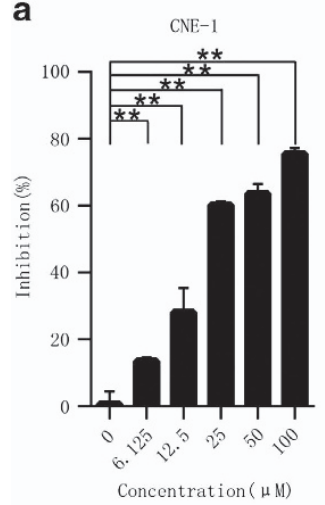

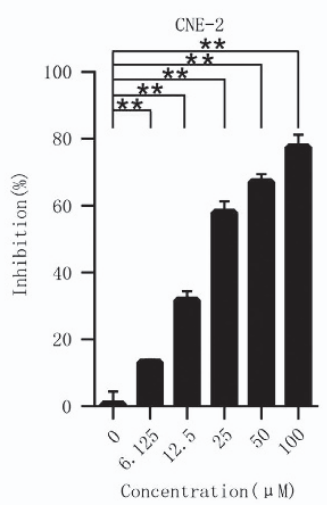
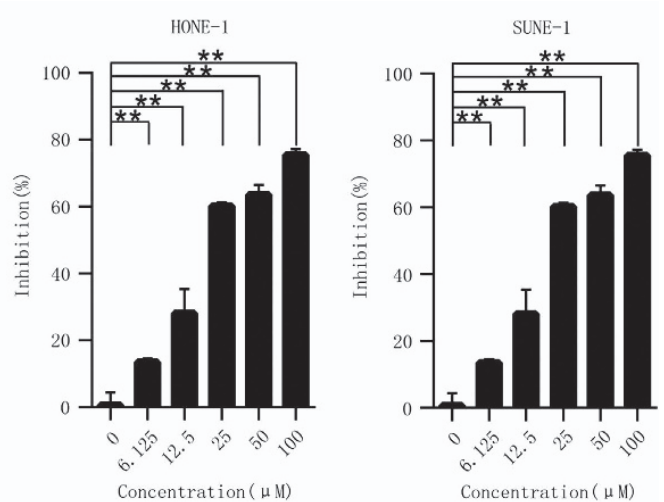

b
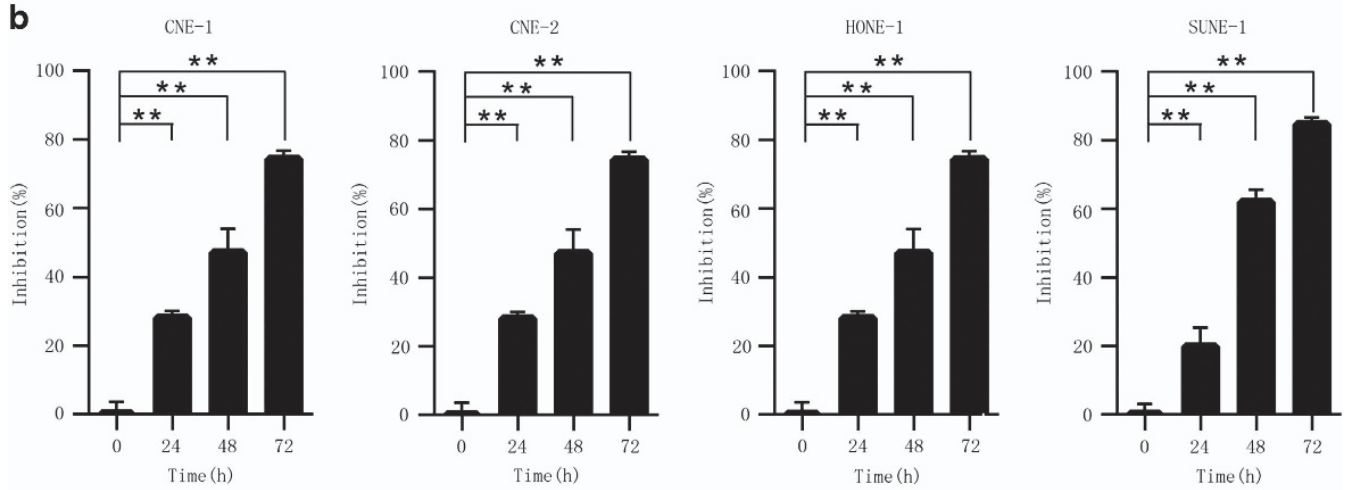

C
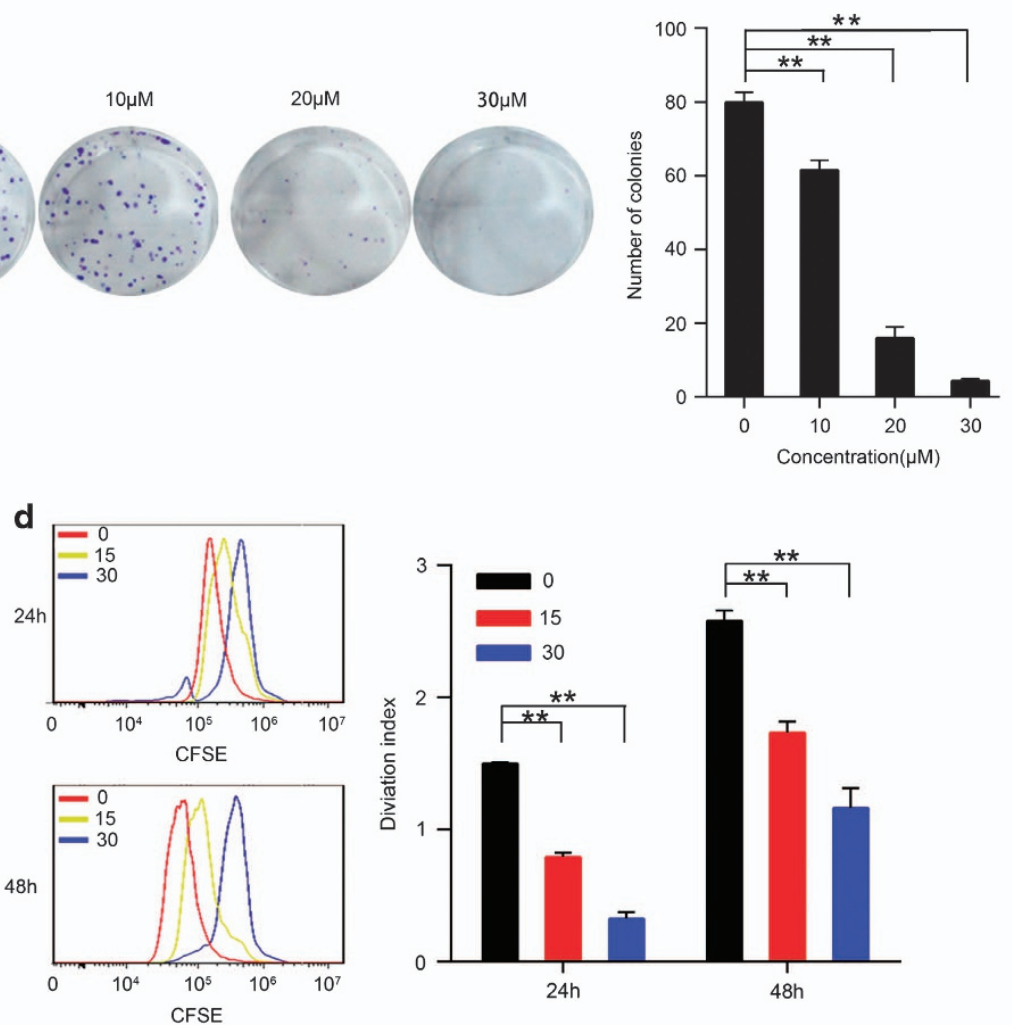

Figure 1 Cardamonin inhibits proliferation and division of NPC cells. (a) CNE-1, CNE-2, HONE-1 and SUNE-1 cells were treated with different concentrations of cardamonin or $0.1 \%$ DMSO for $24 \mathrm{~h}$. Cellular viability was measured with a CCK-8 assay, ${ }^{\star *} P<0.01, n=3$. (b) NPC cells were treated with $10 \mu \mathrm{M}$ cardamonin or $0.1 \%$ DMSO, absorbance was measured after 24,48 and $72 \mathrm{~h}$ of treatment. (c) CNE-2 cells were cultured for 7 days after treatment with varying concentration of cardamonin, and stained with $0.1 \%$ crystal violet. Colonies containing $>50$ cells were counted, ${ }^{* *} P<0.01, n=3$. (d) CFSE labeled cells were measured using flow cytometry after treatment with cardamonin. ${ }^{* *} P<0.01$, $n=3$ 
concentration-dependent manner (Figure 1c). As carboxyfluorescein diacetate succinimidyl ester (CFSE) fluorescence intensity reduced by one half at each cell division, the proliferation of CFSE-labeled cells can be monitored through fluorescence intensity. ${ }^{20}$ A rapid decrease of fluorescence intensity was observed in CFSE-labeled CNE-2 cells after $24 \mathrm{~h}$ (Figure 1d), demonstrating rapid proliferation of CNE-2 cells, while fluorescence intensity of CNE-2 cells treated with cardamonin stayed at high level.

Cardamonin induces apoptosis in CNE-2 cells. To further determine the mechanism of cell death of CNE-2 cells induced by cardamonin, the method of Annexin V-FITC/PI double staining was used. Treatment with cardamonin for $24 \mathrm{~h}$ resulted in increased numbers of apoptotic cells (Figure 2a). Cardamonin at $15 \mu \mathrm{M}$ increased apoptotic cells in a time-dependent manner (Figure 2b). Consistently, PARP and caspase 8 cleavage were activated by cardamonin in a concentration-dependent manner (Figure 2c). Noticeably, the expression level of the proapoptotic effector protein Bax and
Bid was also markedly increased after treatment with cardamonin in CNE-2 cells.

Cardamonin induces G2/M phase arrest in CNE-2 cells. To investigate the mechanism of antiproliferative effects, a cell cycle detection kit was used to evaluate the effect of cardamonin on the cell cycle distribution. As shown in Figure 2d, cardamonin treatment significantly increased the percentage of cells in the G2/M phase in CNE-2 cells. We next focused on the mechanism by which cardamonin induced G2/M phase arrest in CNE-2 cells. P21 and p53 are very important to sustain the G2/M phase after DNA damage. ${ }^{21}$ Given that cardamonin treatment induced G2/M phase arrest, we evaluated the effect of cardamonin on expression of p21 and p53. Figure $2 e$ showed that treatment with cardamonin resulted in a concentration-dependent increase in the expression of p21 and p53. Cyclin D1 was markedly reduced, suggesting that cardamonin induced G2/ $\mathrm{M}$ arrest through regulation of p21, p53 and Cyclin D1.

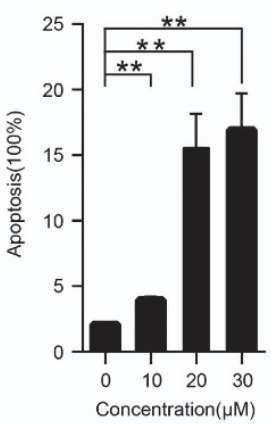

b

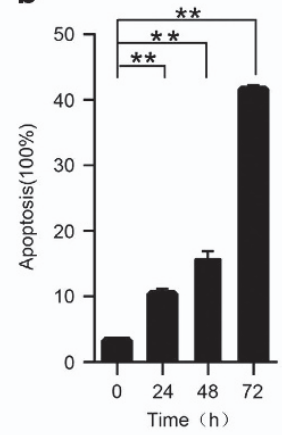

C

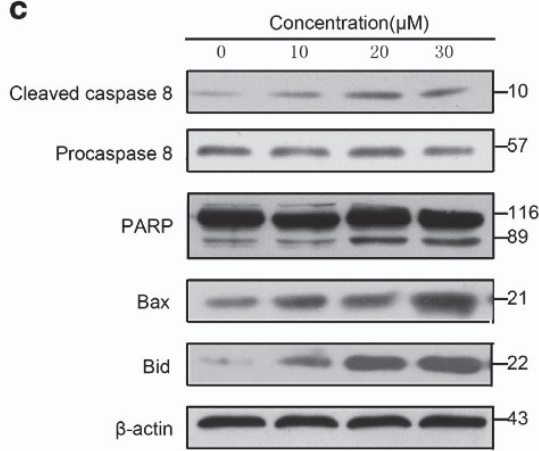

d
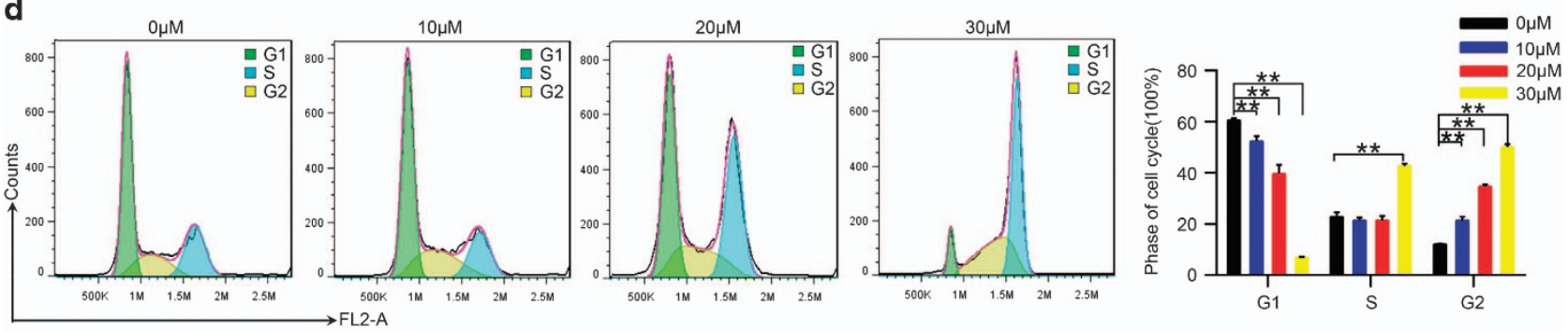

e
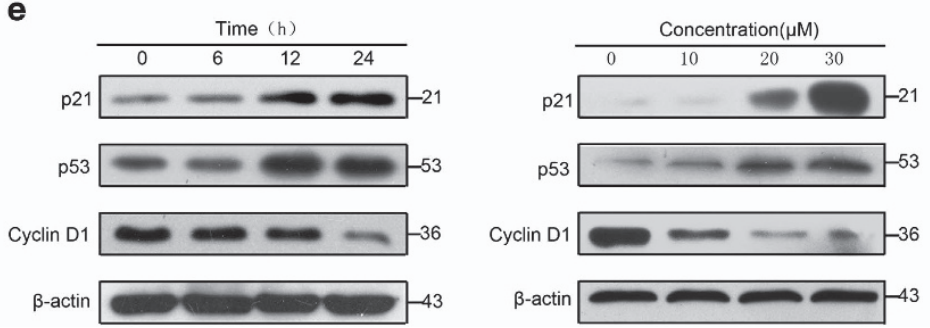

Figure 2 Cardamonin induces apoptosis and G2/M phase arrest in CNE-2 cells. (a) CNE-2 cells were cultured with indicated concentrations of cardamonin for $24 \mathrm{~h}$, apoptosis was measured using Annexin V-FITC and PI staining method. ${ }^{* *} P<0.01, n=3$. (b) CNE-2 cells were treated with $20 \mu \mathrm{M}$ of cardamonin for different time, apoptosis was measured using Annexin V-FITC and PI staining method. ${ }^{\star *} P<0.01, n=3$. (c) Bid, Bax, Cleavage of caspase 8 , caspase 8 and PARP were evaluated by western blot. (d) Cell cycle analysis after treatment with varying concentrations of cardamonin for $24 \mathrm{~h} .{ }^{* \star} \mathrm{P}<0.01$. (e) The protein expression of p53, p21 and Cyclin D1 was evaluated by western blotting after treatment with cardamonin 
Cardamonin induces growth inhibition in a ROS-dependent manner. Accumulation of ROS has been implicated in many aspects in control of cellular proliferation and apoptosis. ${ }^{22}$ We therefore assessed ROS accumulation after cardamonin treatment using the fluorescent probe DCFH-DA.

Treatment with cardamonin induced accumulation of ROS in a

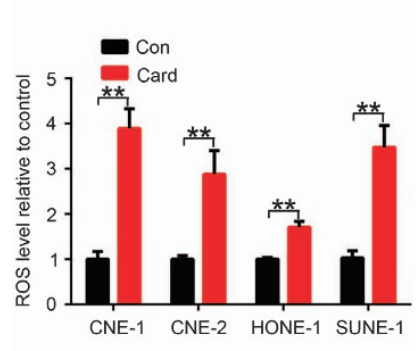

C
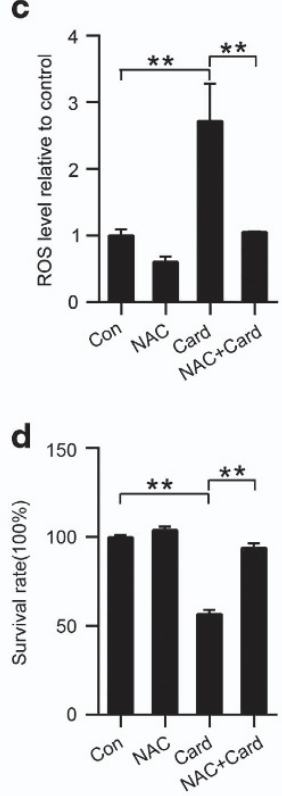

e

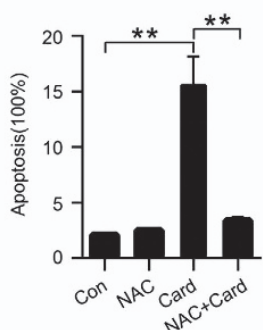

b

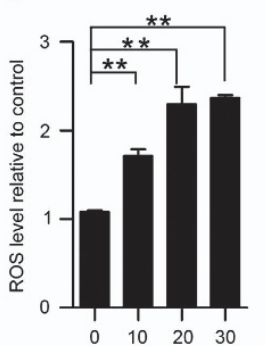

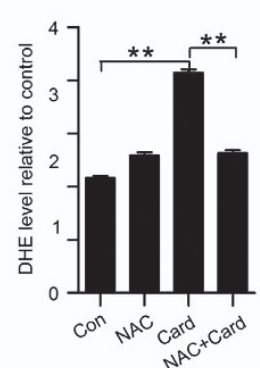
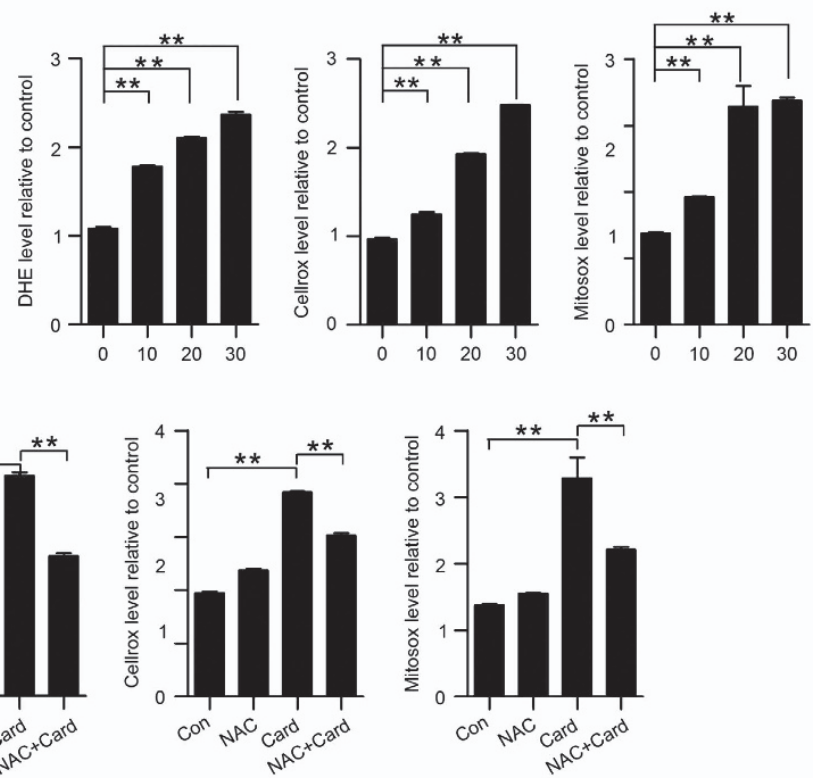

$\mathbf{f}$
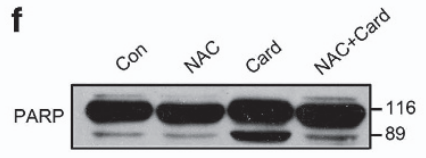

Bax

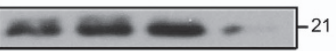

Bid

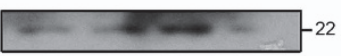

$\beta$-actin

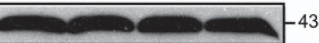

g
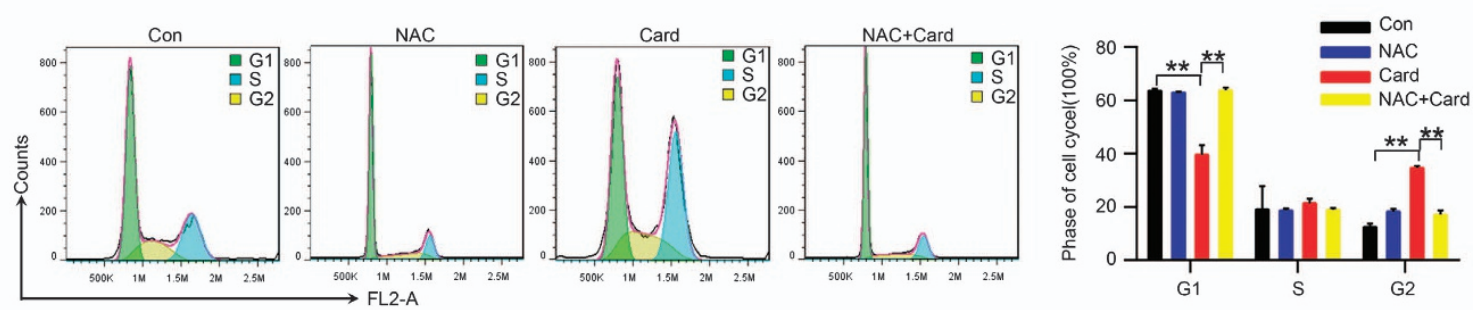

h
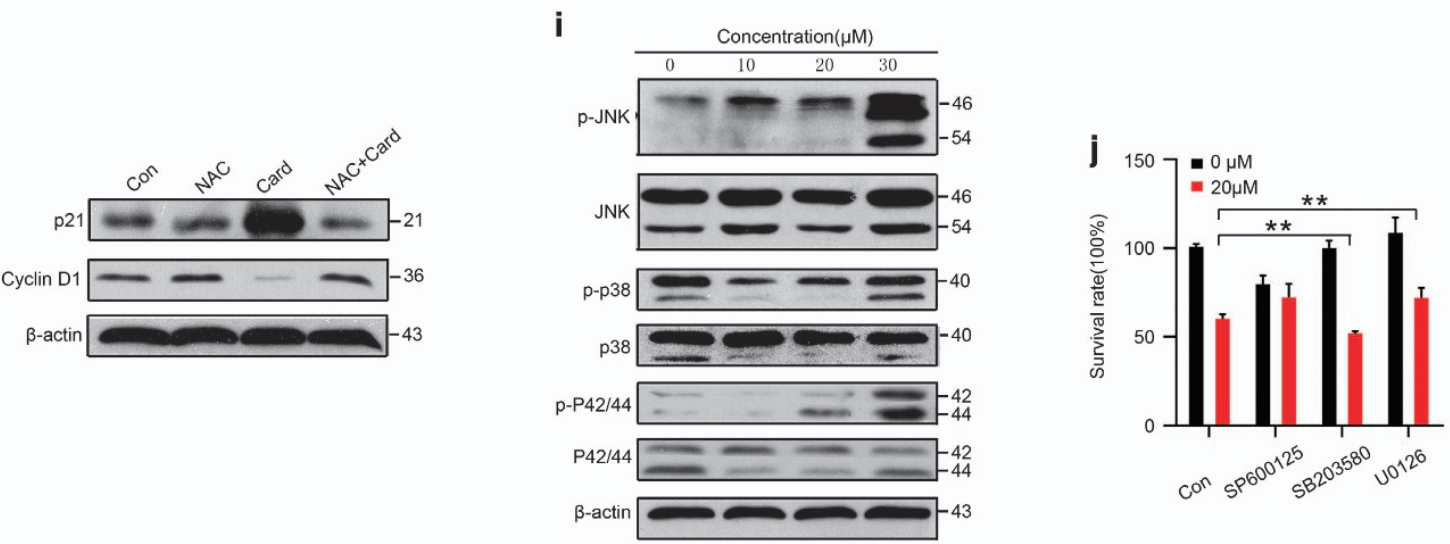
CNE-1, CNE-2, HONE-1 and SUNE-1 cells (Figure 3a). Similar results were observed in CNE-2 cells using other ROS-sensitive dyes, DHE, CellRox and MitoSOX (Figure 3b).

To determine whether the accumulation of ROS is critical for growth inhibition induced by cardamonin, cellular viability was examined in the presence or absence of ROS scavenger NAC with cardamonin treatment. In the absence of NAC, treatment with cardamonin showed ROS accumulation and growth inhibition in CNE-2 cells. As expected, ROS accumulation induced by cardamonin decreased in the presence of NAC. This reduction in ROS accumulation corresponded to a decrease in cell inviability induced by cardamonin (Figures $3 c$ and $d$ ). These results suggested that ROS play an important role in the action of cardamonin.

Cardamonin-induced apoptosis is mediated through the induction of PARP cleavage. We next tested the effect of cardamonin on apoptosis in CNE-2 cells in the presence of NAC. Figure $3 e$ showed that cardamonin-induced apoptosis was effectively decreased by NAC. In addition, the expression of Bax, Bid and cleavage of PARP induced by cardamonin was attenuated upon exposure of NAC (Figure 3f). These data show that cardamonin exerted its effect in CNE-2 cells by accumulating ROS, which then contribute to cleavage of PARP and apoptosis.

Cardamonin-induced $\mathrm{G} 2 / \mathrm{M}$ phase arrest is mediated through the regulation of cell-cycle-related proteins. To confirm the role of ROS on cardamonin-induced G2/M phase arrest, cell cycles were examined with and without NAC. As shown in Figure $3 \mathrm{~g}$, treatment with NAC resulted in a significant decrease of G2/M phase arrest induced by cardamonin in CNE-2 cells. Consistently, the changes in expression of Cyclin D1 and p21 induced by cardamonin were reversed in the presence of NAC (Figure 3h). Overall, our results suggest that increased expression of Cyclin D1 and p21 induced by ROS participated in cardamonin-induced G2/M phase arrest.

Cardamonin induces JNK MAPK activation. Previous reports have established that ROS trigger MAPK and subsequent cell death. ${ }^{23,24}$ To gain further insight into the molecular mechanism of cardamonin induced inviability, we investigated the expression and phosphorylation of JNK, p42/44 and p38 MAPK in CNE-2 cells. Here, significant increases of phosphorylation in JNK, p42/44 and p38 MAPK were noticed while there seemed to be no obvious change in total JNK, p42/44 and p38 MAPK after treatment with cardamonin (Figure $3 \mathrm{i}$ ). To confirm the regulatory role of MAPK in cardamonin-induced inviability, CNE-2 cells were treated with JNK, p42/44 and p38 inhibitor. Treatment with JNK inhibitor (SP600125) and p42/44 inhibitor (U0126) partially reversed the inhibitory effect of cardamonin. In contrast, the p38 inhibitor (SB203580) had no significant effect on the viability of CNE-2 cells (Figure $3 \mathrm{~g}$ ). Taken together, the above results indicate that activation of JNK was involved in the effects of cardamonin.

Cardamonin-induced accumulation of ROS is mediated through inhibition of the NF- $\mathbf{B}$ pathway. There are many proteins participating in the regulation of ROS, such as G6PD, GCLM, COX2, SOD1, SOD2, GSTM1, GSTM2, GSTM3, GSTM4 and GSTM5. To further investigate the underlying mechanism involved in the regulation of ROS, these genes were examined using real-time RT-PCR. We observed significantly decreased expression of GCLM, SOD2, GSTM1, GSTM2, GSTM3 and GSTM4 following treatment with cardamonin. Expression of SOD1 was not affected by cardamonin. Interestingly, all these genes involved are target genes of NF-kB and Nrf2. At the same time, previous data from our laboratory showed that NF- $k B$ and Nrf2 participated in the function of cardamonin. Consequently, we investigated whether there was a link between ROS-accumulating activity of cardamonin and NF- $k \mathrm{~B}$ and Nrf2 pathway. Significant increase of nuclear Nrf2 was observed in CNE-2 cells following treatment with cardamonin for $12 \mathrm{~h}$, which was not consistent with downregulation of GCLM, SOD2 and GSTMs. We suspected that NF- $\kappa$ B plays an important role in regulation of ROS.

First, we tested whether inhibition of the NF-kB pathway also occurred in CNE-2 cells. NF- $\kappa$ B p65, a major subunit of NF- $\kappa \mathrm{B}$, is phosphorylated and translocates to the nucleus upon activation. ${ }^{25}$ P65 exerts its function as a transcription factor via binding to specific DNA sequences and promoting the transcription of target genes. Therefore, activation of the NF- $\kappa$ B pathway was monitored by measuring the localization and phosphorylation of p65 (Figure 4b). Significant reduction of nuclear p65 protein was observed in CNE-2 cells following treatment with cardamonin for $12 \mathrm{~h}$ (Figure 4c). Consistently, phosphorylation of p65 was inhibited in a time- and concentration-dependent manner. In addition, treatment with cardamonin showed a significant decline in the phosphorylation of $I_{K} \mathrm{~B} a$ and expression of $\mathrm{IKK} a$ and $\mathrm{IKK} \beta$ as early as $6 \mathrm{~h}$. These results demonstrated that cardamonin inhibited activity of the NF-KB pathway. IKKa and IKK $\beta$ and phosphorylation of $I_{\kappa} \mathrm{B} a$ were involved in the process (Figure $4 \mathrm{~b}$ ).

Next, we attempted to identify the role of the NF- $\kappa$ B pathway in accumulation of ROS. Figure $4 \mathrm{~d}$ shows that inhibition of the NF- $\kappa$ B pathway was accompanied by increased ROS accumulation as indicated. Intracellular ROS levels were measured

Figure 3 Cardamonin inhibited CNE-2 cells in a ROS- and JNK-dependent manner. (a) NPC cells were treated with cardamonin for $24 \mathrm{~h}$ and intracellular ROS were evaluated by flow cytometry using DCFH-DA. ${ }^{*} P<0.01, n=3$. (b) CNE-2 cells were treated with cardamonin for $24 \mathrm{~h}$ and intracellular ROS were evaluated by flow cytometry using DCFH-DA, MitoSOX, CellRos and DHE. ${ }^{* *} P<0.01, n=3$. CNE-2 cells were treated with $20 \mu \mathrm{M}$ cardamonin with or without 10 mM NAC, then intracellular ROS (c), cell viability (d), apoptosis (e), expression of Bid, Bax and PARP (f), cell cycle (g) and expression of Cyclin D1 and p21 (h) were measured. (i) Expression of p-JNK, JNK, p-p38 MAPK, p38 MAPK, p-p42/44 MAPK and p42/44 MAPK were evaluated by western blotting after treatment with indicated concentration of cardamonin for 24 h. (j) CNE-2 cells were treated with JNK inhibitor (SP600125), p38 inhibitor (SB203580), p42/44 inhibitor (U0126) with or without cardamonin and cellular viability were measured with a CCK-8 assay 
a

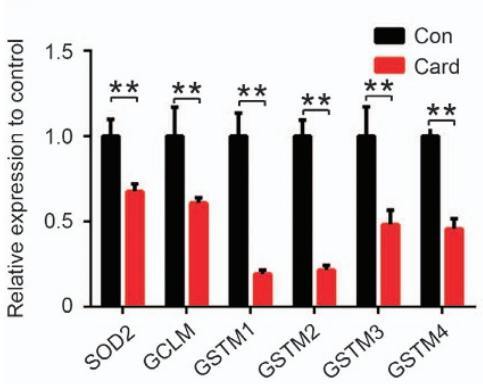

b

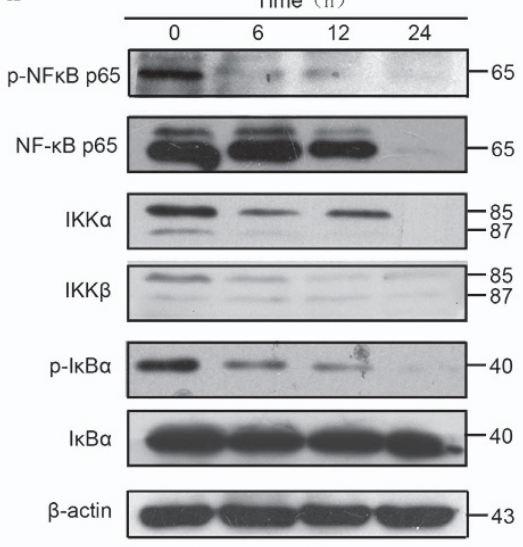

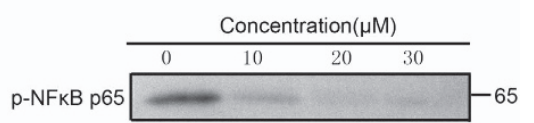

NF-KB p65 $=-\cdots-65$
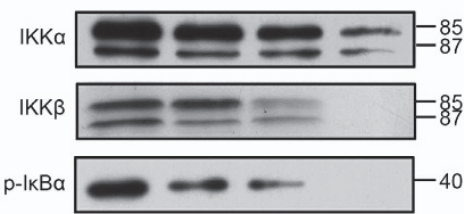

IKBa

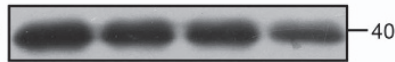

$\beta$-actin

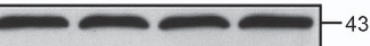

c
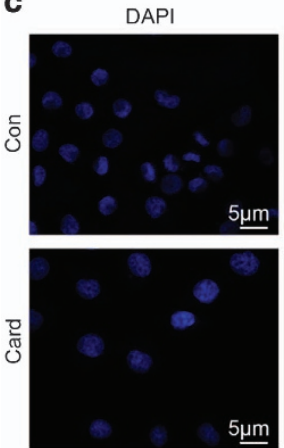

NF-KB
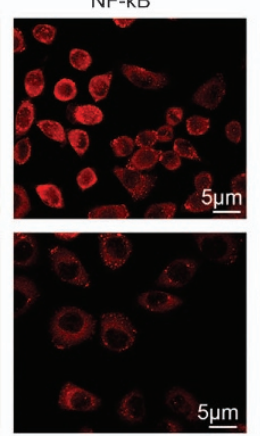

e

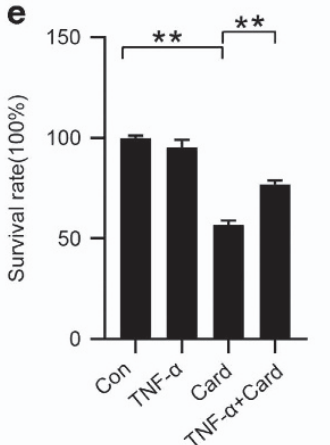

d
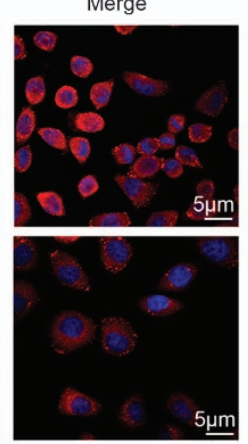

$5 \underline{\underline{\mu m}}$
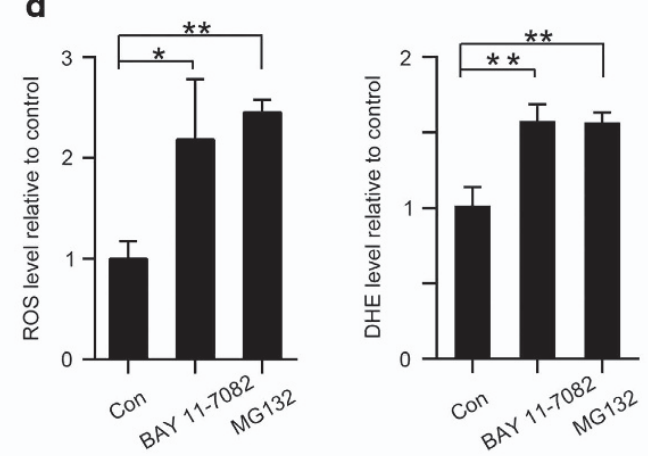

f

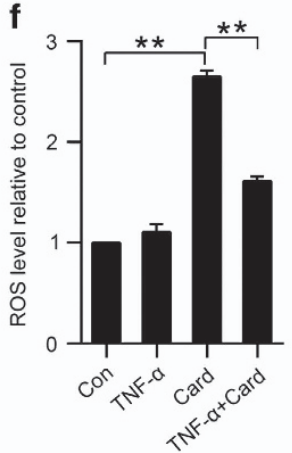

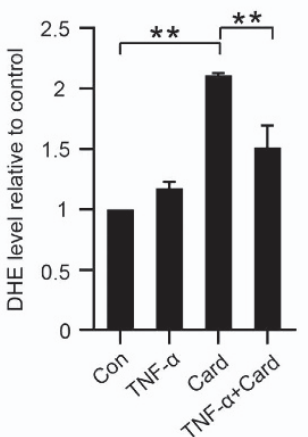

Figure 4 Cardamonin-induced accumulation of ROS is mediated through the inhibition of the NF- $\kappa$ B pathway. (a) Expression of SOD2, GCLM, GSTM1, GSTM2, GSTM3 and GSTM4 were measured by real-time PCR after treatment with $20 \mu \mathrm{M}$ of cardamonin for $4 \mathrm{~h}$. ${ }^{\star *} P<0.01, n=3$. (b) After treatment with cardamonin for the indicated concentrations or indicated time, expression of $\mathrm{p}-\mathrm{NF}-\kappa \mathrm{B}, \mathrm{NF}-\kappa \mathrm{B}, \mathrm{IKK} \alpha, \mathrm{IKK} \beta, \mathrm{p}-\mathrm{I} \kappa \mathrm{B}$ and $\mathrm{l} \kappa \mathrm{B}$ were evaluated by western blotting. (c) CNE-2 cells were cultured with $20 \mu \mathrm{M}$ cardamonin or $0.1 \% \mathrm{DMSO}$ for $12 \mathrm{~h}$ and then the intracellular distribution of NF- $\kappa \mathrm{B}$ was analyzed by immunofluorescence. (d) After treatment with NF- $\kappa \mathrm{B}$ inhibitors in the present of cardamonin, intracellular ROS levels were measured using DCFH-DA and DHE, ${ }^{* \star} P<0.01, n=3$. (e) CNE-2 cells were treated with $20 \mu \mathrm{M}$ cardamonin with or without TNF- $\alpha$ cell viability was measured. ${ }^{\star \star} P<0.01, n=3$. (f) After treatment with NF- $\kappa$ B activator TNF- $\alpha$ in the presence of cardamonin, intracellular ROS levels were measured using DCFH-DA and DHE ${ }^{* *} P<0.01, n=3$

in the presence and absence of NF-KB activator TNF- $a$. Cellular viability was examined in the presence or absence of TNF- $a$ with cardamonin treatment. Decreased cell viability induced by cardamonin was partially attenuated upon exposure of TNF- $a$ (Figure 4e). As can be seen in Figure 4f, in the absence of TNF- $a$, treatment with cardamonin showed a significant increase of ROS accumulation, whereas the elevation of ROS accumulation induced by cardamonin was partially blocked in the presence of TNF- $\alpha$. To confirm the regulatory role of the NF- $\kappa B$ pathway in cardamonin-induced accumulation of ROS, cells were treated with NF-KB inhibitor BAY 11-7082 and MG132 and assessed. Taken together, cardamonin induced ROS accumulation via inhibition of the NF-KB pathway.

Cardamonin inhibits tumor growth in vivo without serious side effects. We carried out the in vivo studies in nude mice xenografted with CNE-2 cells. Xenografts were administrated solvent, cardamonin and cisplatin intraperitoneally. Here, we found that both cardamonin and cisplatin 
a

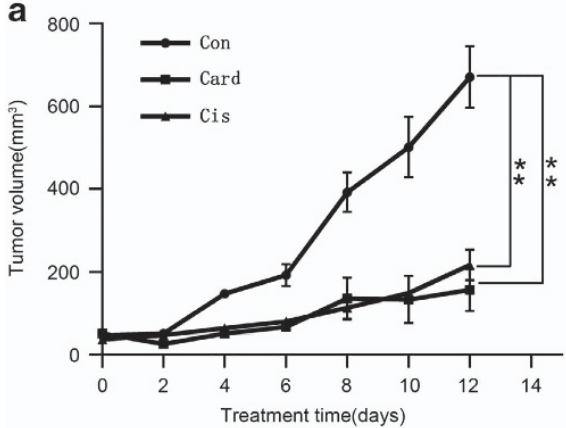

d

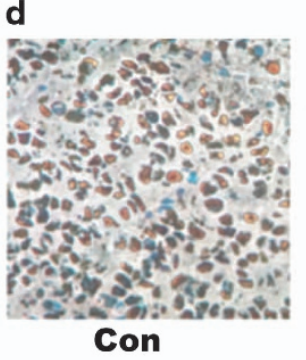

e

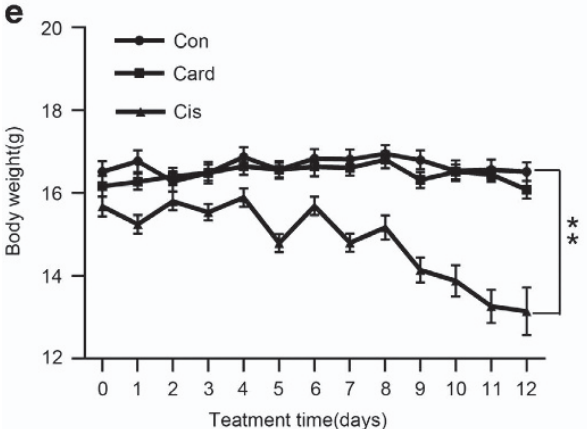

b

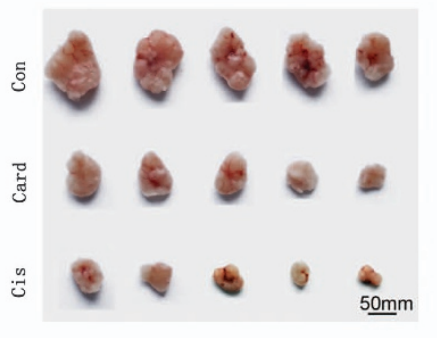

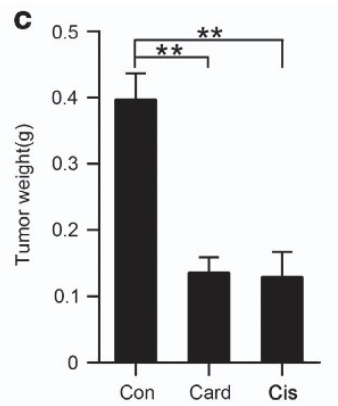

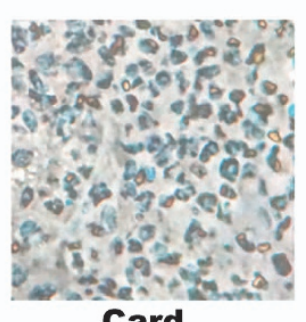

Card

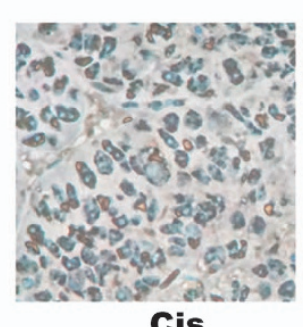

Cis
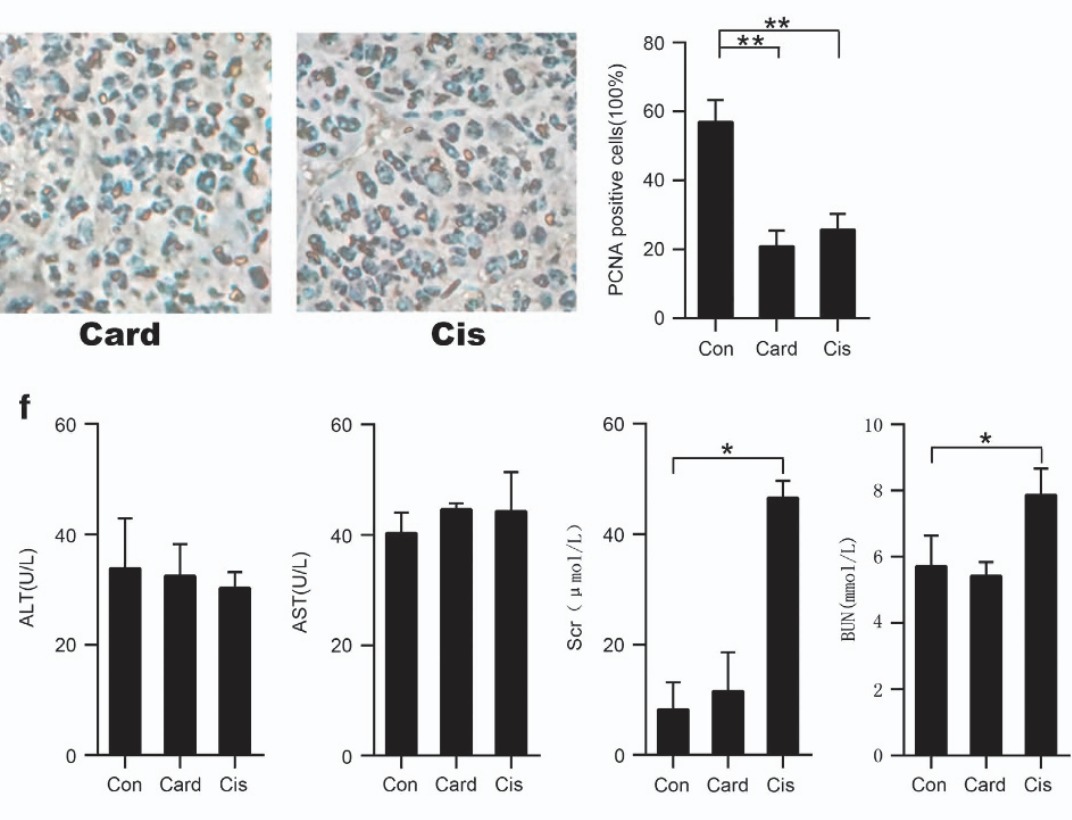

Figure 5 Cardamonin inhibits tumor growth in vivo without serious side effects. (a) Tumor volume was measured every other day and plotted. (b) Tumors for each group were photographed. (c) Tumor weight was measured after being killed. (d) Tumors were stained with PCNA and analyzed using histochemistry. (e) Body weights of each group were measured every day. (f) ALT, AST, BUN, Scr in serum were evaluated for each group. ${ }^{*} P<0.05,{ }^{* *} P<0.01, n=5$

exhibited a significant growth-inhibiting effect in vivo (Figures $5 \mathrm{a}$ and b). While there was no significant difference in tumor volume and weight between the two groups. The tumor growth inhibition ratio of cardamonin and cisplatin was $58.89 \%$ and $62.12 \%$, respectively (Figure $5 \mathrm{c}$ ). Cisplatin caused dramatic loss in body weight and impaired renal function (Figures $5 e$ and f). In contrast, cardamonin did not cause any weight changes or adversely affect hepatic or renal functions.

\section{Discussion}

In this study, we demonstrated that cardamonin possesses anti-cancer ability in NPC models (in vitro and in vivo). Mechanistically, our data showed that cardamonin triggers apoptosis and a G2/M phase arrest to mediate cell death via accumulation of ROS. Furthermore, we demonstrated that cardamonin induces ROS accumulation in NPC cells by decreasing NF- $\kappa \mathrm{B}$ transcriptional activity, resulted in decreasing expression of anti-oxidative genes. To our knowledge, this is the first report demonstrating that cardamonin can induce G2/M phase arrest and apoptosis through accumulation of ROS.

It has been reported that cardamonin is effective against multiple kinds of cancers including lung cancer, multiple myeloma, glioblastoma and colorectal carcinoma. ${ }^{15,16,18,26,27}$ $\mathrm{IC}_{50}$ values for $24 \mathrm{~h}$ were estimated to be $15-50 \mu \mathrm{M}$. Treatment with cardamonin analog dimethyl cardamonin for $24 \mathrm{~h}$ and cell proliferation of HCT116 and LOVO cells were inhibited by about 40 and $37 \%$ at a dose of $40 \mu \mathrm{M} .{ }^{28}$ Whether cardamonin is effective against NPC cells was a question. In our studies, cardamonin was very effective in inhibiting proliferation of CNE-1, CNE-2 and HONE-1 cells (with $I_{50}$ values about $15 \mu \mathrm{M}$ : Figure 1a), while SUNE-1 cells were not sensitive to cardamonin treatment. This suggested that cardamonin inhibits NPC cells selectively. In in vivo studies, cardamonin at $5 \mathrm{mg} / \mathrm{kg}$ caused a significant decrease in tumor mass and a $58.89 \%$ growth delay of the tumor. Niu's study showed that lung tumor growth was inhibited by cardamonin in C57BL/6 mice. The tumor growth inhibition ratios were $84.3 \%$ (10.5 mg/ 
$\mathrm{kg}), 71.2 \%(7.0 \mathrm{mg} / \mathrm{kg})$ and $31.6 \%(3.5 \mathrm{mg} / \mathrm{kg})$, respectively. ${ }^{19}$ This further demonstrated that cardamonin suppresses NPC cells.

Previously, apoptosis was believed to be the crucial factor in inducing cell death by cardamonin. Our previous study showed that cardamonin treatment rapidly and efficiently activates apoptosis in multiple myeloma cells. ${ }^{15}$ This process is dependent on the activation of caspase 3 and PARP. In our current study, cardamonin induced apoptosis in CNE-2 cells as evidenced by a time- and concentration-dependent increase in Annexin V staining. Caspase 8 and PARP activation corresponded with activation of apoptosis during cardamonin treatment in CNE-2 cells. In accordance with our study, cardamonin induced apoptosis and activation of Caspase 9 and Caspase 3 in human breast cancer MDAMB-231. ${ }^{29}$ Apoptosis was also observed in glioblastoma, ${ }^{27}$ colorectal carcinoma ${ }^{16}$ and prostate cancer, ${ }^{30}$ with downregulation of cell survival proteins (cIAP-1, cFLIP, XIAP and $\mathrm{Bcl}-2$ ), and upregulation of pro-apoptotic proteins (Bid and bax). However, only a slight increase in apoptosis was seen after exposure to cardamonin for $24 \mathrm{~h}$, suggesting that another mechanism of cell death was functional with short time exposure to cardamonin.

Loss of checkpoint controls that regulate normal passage through the cell cycle is believed to be involved in cancer progression. ${ }^{31}$ Cell cycle arrest participates in the anti-cancer process of many drugs, such as curcumin, ${ }^{32}$ Wentilactone $A^{33}$ and celastrol. ${ }^{23}$ Targeting the cell cycle is a new approach to cancer therapy. ${ }^{34}$ Cardamonin-induced G2/M arrest has been seen in other cancer cells such as colorectal carcinoma ${ }^{16,28}$ and breast cancer cells. ${ }^{35}$ Thus, we suspected that cell cycle arrest plays a pivotal role in the inhibitory effect of cardamonin in CNE-2 cells. The present study confirmed that cardamonin treatment for $24 \mathrm{~h}$ triggered significant G2/M phase arrest in CNE-2 cells. The cell cycle is a series of events tightly integrated and regulated by Cylin/CDK complexes. ${ }^{36}$ The Cdc2/Cyclin B1 complex has been implicated to be involved in G2/M delay under oxidative stress. ${ }^{21,37}$ Through inhibiting dephosphorylation of inhibitory sites on Cdc25C, Chk1 alters Cdc2/Cyclin B1 activity upon stress. ${ }^{38}$ Previous studies of colorectal cancer showed that cardamonin induces phosphorylation of Chk1 and decreases expression of Cyclin B1 and Cdc2, suggesting that the Chk1/Cyclin B1/Cdc2 pathway is involved in cardamonin-induced G2/M phase arrest. ${ }^{16,28}$ The detailed mechanism studies showed that cardamonin caused an increase of p21 and decrease of Cyclin D1 (Figure 2g). Cyclin D1 is a key regulator of the G1 phase. Cyclin D1 deficiency results in cell cycle arrest. ${ }^{39}$ Cyclin D1 decreased readily subsequent to genomic stress in fibroblasts and endothelial cells. ${ }^{40}$ Intriguingly, a Cyclin D1 decrease is accompanied by $\mathrm{G} 2 / \mathrm{M}$ arrest in response to ROS. A subsequent study shows that Chk1 plays a key role in this process. ${ }^{41,42}$ Cyclins and CDKs are further regulated by the Cip/Kip protein family (p21, p27 and p57) and Ink4 protein family (p15, p16, p18 and p19). ${ }^{31}$ As an inhibitor of CDKs, induced expression of $\mathrm{p} 21$ is essential to sustain the $\mathrm{G} 2$ arrest after DNA damage in human cells. ${ }^{21}$ P21 suppresses Cyclin B1/Cdc2 activity by binding with Cdc2 directly, thus inhibiting the G2/M transition. ${ }^{43}$ Our data suggested that the G2/M arrest induced by cardamonin likely result from a synergistic mechanism involving the activation of p21 and suppression of Cyclin D1 expression.

Accumulating evidence suggests that many types of cancer cells exhibit increased levels of ROS. ROS production has long been proved to be associated with apoptosis and G2/M arrest caused by anticancer agents. ${ }^{6,8}$ ROS accumulation is observed in colorectal cancer cells after treatment of cardamonin. ${ }^{16}$ Our present study found that cardamonin increases oxidative stress in NPC cells. Accordingly, apoptosis and G2/M phase arrest corresponded with accumulation of ROS in NPC cells, suggesting its importance in the anti-cancer activity of cardamonin. What is more, cellular viability, apoptosis and G2/M phase arrest were attenuated by NAC, further pointing out that ROS play a piovital role in cardamoninmediated cell inviability. The MAPKs, p38 and JNKs, have been implicated in apoptotic signaling in response to increased generation of ROS. ${ }^{24}$ Consistent with these findings, the JNK pathway was demonstrated to be involved in cardamonin-induced inhibition of proliferation in colon nasopharyngeal cells, further establishing ROS as the target of cardamonin in CNE-2 cells.

The NF- $\kappa$ B pathway is closely related with ROS. On the one hand, accumulation of ROS triggers activation of the NF- $k B$ pathway. On the other hand, activation of the NF- $\kappa$ B pathway modulates the generation and elimination of ROS. ${ }^{44}$ A pivotal effector of antioxidant is ferritin heavy chain (FHC), the downstream gene of NF- $\mathrm{KB}$. FHC and the light chain form the Ferritin complex, the primary iron storage mechanism in cells. The antioxidant activity of FHC depends on sequestration of free iron, which is a transition metal that catalyzes the formation of ROS in mitochondria and through the Fenton reaction, resulting in the production of highly reactive hydroxyl $(\bullet \mathrm{OH})$ radicals. ${ }^{45}$ Another factor that has been proposed to play an important role as effector of the ROS-inhibiting and cytoprotective actions of NF- $\kappa \mathrm{B}$ is SOD2. ${ }^{46}$ Apart from $\mathrm{FHC}$ and SOD2, there are some other proteins downstream of NF- $k$ B. In the present study, ROS-related gene SOD2, GCLM and GSTMs were decreased with cardamonin treatment. Our previous study in multiple myeloma showed that cardamonin inhibited activation of the NF- $K \mathrm{~B}$ pathway. Inhibition of the NF- $k$ B pathway was confirmed in CNE-2 cells in the present study. We suspected that NF-KB pathway is indispensable to accumulation of ROS induced by cardamonin. Activation of the NF- $K \mathrm{~B}$ pathway by TNF- $a$ partially reversed accumulation of ROS induced by cardamonin, further confirming the modulating effect of the NF- $k B$ pathway on redox balance.

In this study, our novel discovery demonstrate that cardamonin is a potent agent in inducing G2/M arrest and apoptosis in human NPC cells through a NF- $\kappa$ B- and ROS-dependent pathway (Figure 6). This will pave the way for further development of the clinical application of this compound in treating NPC.

\section{Materials and Methods}

Chemicals and antibodies. Cardamonin was purchased from Sigma-Aldrich (St Louis, MO, USA). BAY 11-7082 and MG132 and NAC were purchased from Beyotime Biotechnology (Haimen, China). TNF- $\alpha$, SP600125, SB203580 were from PeproTech Inc. (Rocky Hill, NJ, USA). Cell Counting Kit-8 was from Dojindo Molecular Technologies (Kumamoto, Japan). Anti-NF-kB p65, anti-phospho-p65 anti-CDK4, anti-p21, anti-PARP, anti-JNK, anti-p38 MAPK, anti-phospho-JNK and 


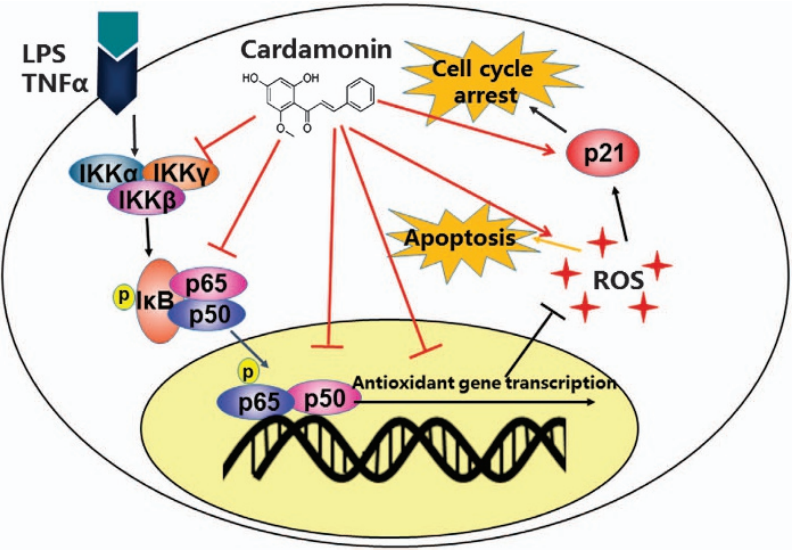

Figure 6 Illustration of possible molecular mechanism of cardamonin-induced inhibitory effect in NPC cells

Table 1 Primers for real-time PCR

\begin{tabular}{lll}
\hline Gene & Forward primer (5' to $\left.\mathbf{3}^{\prime}\right)$ & Reverse primer $\left(\mathbf{3}^{\prime}\right.$ to $\left.\mathbf{5}^{\prime}\right)$ \\
\hline SOD2 & ccctggaacctcacatcaac & agtcacgtttgatggcttcc \\
GCLM & cgcgggatgagtaacggtta & tccaaactgagggagctgtt \\
GSTM1 & actaaagccagcctgacctt & tcaatgctgctccttcatgc \\
GSTM2 & ctcagagtccttgcaacagc & atcaggtgggaacttcaggg \\
GSTM3 & agatggagtccctttggcaa & ctgggaagtcttctgtgggt \\
GSTM4 & tgatgtccttgacctccacc & cttctccaagccctcaaagc \\
SOD1 & caggacctcattttaatcctcac & cccaggtctccaacatgc \\
\hline
\end{tabular}

anti-phospho-p38 MAPK were purchased from Cell Signaling Technology (Danvers, MA, USA).

Cell culture and drug treatment. Human NPC cell lines CNE-1, CNE-2, HONE-1 and SUNE-1 were a generous gift from Prof. Yixin Zeng (Sun Yat-sen University, Guangzhou, China). CNE-1 and CNE-2 cells were cultured in RPMI 1640 medium with $10 \%$ fetal bovine serum (FBS) and $1 \%$ penicillin-streptomycin in a humidified incubator at $37^{\circ} \mathrm{C}$ with $5 \% \mathrm{CO}_{2}$. HONE-1 and SUNE-1 cells were maintained in Dulbecco's modified Eagle's medium supplemented with $10 \%$ FBS at the same condition.

Cell viability assay. Cellular viability was measured with a CCK-8 assay. Cells were seeded in 96-well plates with a density of 5000 cells/well in $100 \mu$ l of medium for $24 \mathrm{~h}$. After treatment for a period of time, $10 \mu \mathrm{l}$ of CCK-8 solution was added and incubated for $2 \mathrm{~h}$, and then absorbance was measured at $410 \mathrm{~nm}$ with a microplate reader.

Apoptosis assay. Apoptosis was detected using an Annexin V-FITC/PI double staining apoptosis detection kit (Nanjing Jiancheng Bioengineering Institute, Jiangsu Province, China). Cells were plated in 24-well plates at a density of $5 \times 10^{4}$ cells/well in $1 \mathrm{ml}$ medium. Cells were collected and washed twice with PBS. Cells were suspended in Annexin-binding buffer and incubated at room temperature for $15 \mathrm{~min}$ in the dark with $5 \mu \mathrm{l}$ Annexin V-FITC and $1 \mu \mathrm{l} \mathrm{PI}$. FITC fluorescence was analyzed by flow cytometry.

Cell cycle assay. The cell cycle was analyzed using a cell cycle detection kit following the manufacturer's protocols (Nanjing Jiancheng Bioengineering Institute). Cells were plated in six-well plates at a density of $10^{5}$ cells/well in $2 \mathrm{ml}$ medium. Cells were collected and fixed in $70 \%$ ethanol at $-20{ }^{\circ} \mathrm{C}$ overnight. After centrifugation at $400 \times g$ for $5 \mathrm{~min}$, cells were suspended in $100 \mu \mathrm{l}$ RNase solution and incubated at $37^{\circ} \mathrm{C}$ for $30 \mathrm{~min}$. Then $400 \mu \mathrm{l} \mathrm{Pl}$ solution was added and incubated for another $30 \mathrm{~min}$ at $4{ }^{\circ} \mathrm{C}$. The cell cycle was analyzed using flow cytometry.
Measurement of ROS. The ROS generation was measured using an oxidation sensitive fluorescent probe (DCFH-DA) according to the manufacturer's protocols (Beyotime Biotechnology). Cells were stained with a $10 \mu \mathrm{M}$ DCFH-DA probe at $37^{\circ} \mathrm{C}$ for $20 \mathrm{~min}$. Cells were washed three times with PBS and the induction of ROS was examined by flow cytometry. Similar procedure was performed using MitoSOX, CellRox (Thermo Fisher, Waltham, MA, USA) and DHE (Beyotime Biotechnology).

Real-time RT-PCR. Cells were plated in six-well plates at a density of $10^{5}$ cells/well in $2 \mathrm{ml}$ medium. Total RNA was extracted from cells using TRIzol reagent (Invitrogen Life Technologies, Carlsbad, Canada) and was reverse transcribed using transcription reagents (Toyobo, Osaka, Japan). The relative quantification of mRNA levels was performed with SYBR-Green Master Mix (Toyobo) using an ABI-7300 real-time PCR system (Applied Biosystems, Carlsbad, USA). The expression of each gene was normalized to the expression of GAPDH. Primer sequences are listed in Table 1.

Western blotting. Cells were collected and lysed on ice for $30 \mathrm{~min}$ in NP40 with protease inhibitor cocktail (Sigma). The protein concentration was measured with a BCA assay kit (Goodbio, Wuhan, China). Protein samples $(30-50 \mu \mathrm{g})$ were separated by SDS-PAGE (6-12\%) and electro-transferred onto a PVDF membrane. The membrane was blocked with $5 \%$ BSA and incubated with specific primary antibodies at $4{ }^{\circ} \mathrm{C}$ overnight. Proteins of interest were detected with appropriate horseradish peroxidase-conjugated secondary antibodies and developed using an ECL kit (Thermo Scientific, Rockford, IL, USA). The protein levels were normalized by $\beta$-actin.

Animal studies. BALB/c nude mice ( 5 weeks old, 16-18 g) were obtained from Rital River Laboratories (Beijing, China). All experiments were carried out according to the National Institutes of Health Guide for Care and Use of Laboratory Animals. PBS $(50 \mu l)$ containing $10^{6}$ cells was injected subcutaneously into the axilla of the right forelimbs of nude mice. Three days after injection, the mice were randomized into three groups: control group (solvent), cisplatin group (2 mg/kg, every other day), and cardamonin group ( $5 \mathrm{mg} / \mathrm{kg}$, everyday). In this experiment, cardamonin was dissolved in solvent, which consisted of $18 \%$ ethanol, $10 \%$ Tween- 80 and $72 \%$ distilled water. Five mice were set up for each group. Tumor volume was measured every other day and was calculated as (length $\times$ width $\left.^{2}\right) / 2$ for 13 days. Then the mice were killed and the tumor was isolated.

Statistical analysis. Data were expressed as the mean \pm S.D. Significant differences between the two groups were analyzed by Student's $t$-test.

\section{Conflict of Interest}

The authors declare no conflict of interest.

Acknowledgements. This work was supported by the National Natural Science Foundation of China (81202962).

\section{Publisher's Note}

Springer Nature remains neutral with regard to jurisdictional claims in published maps and institutional affiliations.

1. McDermott AL, Dutt SN, Watkinson JC. The aetiology of nasopharyngeal carcinoma. Clin Otolaryngol Allied Sci 2001; 26: 82-92.

2. Wei WI, Sham JS. Nasopharyngeal carcinoma. Lancet 2005; 365: 2041-2054.

3. Yeh SA, Tang Y, Lui CC, Huang YJ, Huang EY. Treatment outcomes and late complications of 849 patients with nasopharyngeal carcinoma treated with radiotherapy alone. Int J Radiat Oncol Biol Phys 2005; 62: 672-679.

4. Baujat B, Audry H, Bourhis J, Chan AT, Onat H, Chua DT et al. Chemotherapy in locally advanced nasopharyngeal carcinoma: an individual patient data meta-analysis of eight randomized trials and 1753 patients. Int J Radiat Oncol Biol Phys 2006; 64: 47-56.

5. Bensouda Y, Kaikani W, Ahbeddou N, Rahhali R, Jabri M, Mrabti $\mathrm{H}$ et al. Treatment for metastatic nasopharyngeal carcinoma. Eur Ann Otorhinolaryngol Head Neck Dis 2011; 128: 79-85.

6. Schumacker PT. Reactive oxygen species in cancer cells: live by the sword, die by the sword. Cancer cell 2006; 10: 175-176.

7. Toyokuni S, Okamoto K, Yodoi J, Hiai H. Persistent oxidative stress in cancer. FEBS Lett 1995; 358: 1-3. 
8. Valko M, Leibfritz D, Moncol J, Cronin MT, Mazur M, Telser J. Free radicals and antioxidants in normal physiological functions and human disease. Int J Biochem Cell Biol 2007; 39: 44-84.

9. Goncalves LM, Valente IM, Rodrigues JA. An overview on cardamonin. J Med Food 2014; 17: 633-640.

10. Kim YJ, Ko H, Park JS, Han IH, Amor EC, Lee JW et al. Dimethyl cardamonin inhibits lipopolysaccharide-induced inflammatory factors through blocking NF-kappaB p65 activation. Int Immunopharmacol 2010; 10: 1127-1134.

11. Takahashi A, Yamamoto N, Murakami A. Cardamonin suppresses nitric oxide production via blocking the IFN-gamma/STAT pathway in endotoxin-challenged peritoneal macrophages of ICR mice. Life Sci 2011; 89: 337-342.

12. Yadav VR, Prasad S, Sung B, Aggarwal BB. The role of chalcones in suppression of NF-kappaB-mediated inflammation and cancer. Int Immunopharmacol 2011; 11: 295-309.

13. Chow YL, Lee $\mathrm{KH}$, Vidyadaran $\mathrm{S}$, Lajis $\mathrm{NH}$, Akhtar MN, Israf DA et al. Cardamonin from Alpinia rafflesiana inhibits inflammatory responses in IFN-gamma/LPS-stimulated BV2 microglia via NF-kappaB signalling pathway. Int Immunopharmacol 2012; 12: 657-665.

14. Li YY, Huang SS, Lee MM, Deng JS, Huang GJ. Anti-inflammatory activities of cardamonin from Alpinia katsumadai through heme oxygenase-1 induction and inhibition of NF-kappaB and MAPK signaling pathway in the carrageenan-induced paw edema. Int Immunopharmacol 2015; 25: 332-339.

15. Qin $Y$, Sun $C Y$, Lu FR, Shu XR, Yang D, Chen $L$ et al. Cardamonin exerts potent activity against multiple myeloma through blockade of NF-kappaB pathway in vitro. Leuk Res 2012; 36: $514-520$.

16. Yadav VR, Prasad S, Aggarwal BB. Cardamonin sensitizes tumour cells to TRAIL through ROS- and CHOP-mediated up-regulation of death receptors and down-regulation of survival proteins. Br J Pharmacol 2012; 165: 741-753.

17. Park S, Gwak J, Han SJ, Oh S. Cardamonin suppresses the proliferation of colon cancer cells by promoting beta-catenin degradation. Biol Pharm Bull 2013; 36: 1040-1044.

18. Kim YJ, Kang KS, Choi KC, Ko H. Cardamonin induces autophagy and an antiproliferative effect through JNK activation in human colorectal carcinoma HCT116 cells. Bioorg Med Chem Lett 2015; 25: 2559-2564.

19. Niu PG, Zhang YX, Shi DH, Liu Y, Chen YY, Deng J. Cardamonin inhibits metastasis of Lewis lung carcinoma cells by decreasing mTOR activity. PLoS One 2015; 10: e0127778.

20. Hawkins ED, Hommel M, Turner ML, Battye FL, Markham JF, Hodgkin PD. Measuring lymphocyte proliferation, survival and differentiation using CFSE time-series data. Nat protoc 2007; 2: 2057-2067.

21. Bunz F, Dutriaux A, Lengauer C, Waldman T, Zhou S, Brown JP et al. Requirement for p53 and p21 to sustain G2 arrest after DNA damage. Science 1998; 282: 1497-1501.

22. Mates JM, Segura JA, Alonso FJ, Marquez J. Intracellular redox status and oxidative stress: implications for cell proliferation, apoptosis, and carcinogenesis. Arch Toxicol 2008; 82 273-299.

23. Li H-Y, Zhang J, Sun L-L, Li B-H, Gao H-L, Xie T et al. Celastrol induces apoptosis and autophagy via the ROS/JNK signaling pathway in human osteosarcoma cells: an in vitro and in vivo study. Cell Death Dis 2015; 6: e1604.

24. Mao X, Yu CR, Li WH, Li WX. Induction of apoptosis by shikonin through a ROS/JNKmediated process in Bcr/Abl-positive chronic myelogenous leukemia (CML) cells. Cell Res 2008; 18: 879-888

25. Hayden MS, Ghosh S. Shared principles in NF-kappaB signaling. Cell 2008; 132: 344-362.

26. Tang $Y$, Fang $Q$, Shi D, Niu $P$, Chen $Y$, Deng J. mTOR inhibition of cardamonin on antiproliferation of A549 cells is involved in a FKBP12 independent fashion. Life Sci 2014; 99 : 44-51.

27. Wu N, Liu J, Zhao X, Yan Z, Jiang B, Wang $L$ et al. Cardamonin induces apoptosis by suppressing STAT3 signaling pathway in glioblastoma stem cells. Tumor Biol 2015; 36 9667-9676.

28. Ko H, Kim YJ, Amor EC, Lee JW, Kim HC, Kim HJ et al. Induction of autophagy by dimethy cardamonin is associated with proliferative arrest in human colorectal carcinoma HCT116 and LOVO cells. J Cell Biochem 2011; 112: 2471-2479.

29. Mi XG, Song ZB, Sun LG, Bao YL, Yu CL, Wu Y et al. Cardamonin inhibited cell viability and tumorigenesis partially through blockade of testes-specific protease 50 -mediated nuclear factor-kappaB signaling pathway activation. Int J Biochem Cell Biol 2016; 73: 63-71.
30. Zhang J, Sikka S, Siveen KS, Lee JH, Um JY, Kumar AP et al. Cardamonin represses proliferation, invasion, and causes apoptosis through the modulation of signal transducer and activator of transcription 3 pathway in prostate cancer. Apoptosis 2016; 22: 158-168.

31. Hartwell LH, Kastan MB. Cell cycle control and cancer. Science 1994; 266: 1821-1828.

32. Choudhuri T, Pal S, Das T, Sa G. Curcumin selectively induces apoptosis in deregulated cyclin D1-expressed cells at G2 phase of cell cycle in a p53-dependent manner. J Biol Chem 2005; 280: 20059-20068.

33. Lv C, Hong Y, Miao L, Li C, Xu G, Wei S et al. Wentilactone A as a novel potential antitumor agent induces apoptosis and G2/M arrest of human lung carcinoma cells, and is mediated by HRas-GTP accumulation to excessively activate the Ras/Raf/ERK/p53-p21 pathway. Cell death dis 2013; 4: e952.

34. Schwartz GK, Shah MA. Targeting the cell cycle: a new approach to cancer therapy. J Clin Oncol 2005; 23: 9408-9421.

35. Shrivastava S, Jeengar MK, Thummuri D, Koval A, Katanaev VL, Marepally $S$ et al. Cardamonin, a chalcone, inhibits human triple negative breast cancer cell invasiveness by downregulation of Wnt/beta-catenin signaling cascades and reversal of epithelialmesenchymal transition. BioFactors 2016; 43: 152-169.

36. Elledge SJ. Cell cycle checkpoints: preventing an identity crisis. Science 1996; 274: 1664-1672.

37. Taylor WR, Stark GR. Regulation of the G2/M transition by p53. Oncogene 2001; 20: 1803-1815.

38. Liu Q, Guntuku S, Cui XS, Matsuoka S, Cortez D, Tamai K et al. Chk1 is an essential kinase that is regulated by Atr and required for the G(2)/M DNA damage checkpoint. Genes dev 2000; 14: 1448-1459.

39. Baldin V, Lukas J, Marcote MJ, Pagano M, Draetta G. Cyclin D1 is a nuclear protein required for cell cycle progression in G1. Genes dev 1993; 7: 812-821.

40. Fasanaro $P$, Magenta A, Zaccagnini G, Cicchillitti L, Fucile S, Eusebi $F$ et al. Cyclin D1 degradation enhances endothelial cell survival upon oxidative stress. FASEB j 2006; 20 : 1242-1244.

41. Pagano M, Theodoras AM, Tam SW, Draetta GF. Cyclin D1-mediated inhibition of repair and replicative DNA synthesis in human fibroblasts. Genes dev 1994; 8 : $1627-1639$.

42. Pyo $\mathrm{CW}$, Choi JH, Oh SM, Choi SY. Oxidative stress-induced cyclin D1 depletion and its role in cell cycle processing. Biochim biophys acta 2013; 1830: 5316-5325.

43. Dash BC, El-Deiry WS. Phosphorylation of p21 in G2/M promotes cyclin B-Cdc2 kinase activity. Mol Cell Biol 2005; 25: 3364-3387.

44. Morgan MJ, Liu ZG. Crosstalk of reactive oxygen species and NF-kappaB signaling. Cell Res 2011; 21: 103-115

45. Bubici C, Papa S, Pham CG, Zazzeroni F, Franzoso G. The NF-kappaB-mediated control of ROS and JNK signaling. Histol histopathol 2006; 21: 69-80.

46. Djavaheri-Mergny M, Javelaud D, Wietzerbin J, Besancon F. NF-kappaB activation prevents apoptotic oxidative stress via an increase of both thioredoxin and MnSOD levels in TNFalpha-treated Ewing sarcoma cells. FEBS Lett 2004; 578: 111-115.

(1) Cell Death and Disease is an open-access journal published by Nature Publishing Group. This work is licensed under a Creative Commons Attribution 4.0 International License. The images or other third party material in this article are included in the article's Creative Commons license, unless indicated otherwise in the credit line; if the material is not included under the Creative Commons license, users will need to obtain permission from the license holder to reproduce the material. To view a copy of this license, visit http://creativecommons.org/licenses/by/4.0/

(C) The Author(s) 2017 